\title{
APLIKASI KENAIKAN GAJI BERKALA MENGGUNAKAN BAHASA PEMROGRAMAN PHP PADA DINAS PENDIDIKAN DAN KEBUDAYAAN KOTA DUMAI
}

\author{
Sukri Adrianto ${ }^{1}$, Sri Wahyuni ${ }^{2}$ \\ ${ }^{1,2}$ Sekolah Tinggi Manajemen Informatika Dan Komputer (STMIK) Dumai \\ JL. Utama Karya Kel. Bukit Batrem Kec. Dumai Timur, Dumai-Riau 28811 \\ e-mail : sukriadrianto@ gmail.com ${ }^{1}$, sri.wahyuniis2406@ gmail.com²
}

\begin{abstract}
ABSTRAK
Dinas Pendidikan dan Kebudayaan Kota Dumai adalah salah satu instansi pemerintah yang bergerak di bidang pendidikan dan didalamnya terdapat kegiatan kenaikan gaji berkala. Dalam pengolahan data kenaikan gaji berkala masih menggunakan cara manual dengan cara melihat dari tabel gaji, sehingga dalam pembuatan SK kenaikan gaji memerlukan waktu yang relatif lama. sampai saat ini Dinas Pendidikan dan Kebudayaan Kota Dumai masih mengalami kesulitan dalam menemukan arsip data guru SD yang mengajukan kenaikan gaji berkala, serta masih lambatnya proses pengajuan gaji berkala karena masih memakai sistem manual. Oleh karena itu diperlukan suatu aplikasi untuk memberikan solusi pada permasalahan tersebut. Dalam penelitian ini aplikasi yang akan dikembangkan adalah aplikasi kenaikan gaji berkala pada Dinas Pendidikan dan Kebudayaan Kota Dumai, sehingga bisa dikembangkan lebih lanjut demi kemajuan dan kepentingan instansi seiring dengan perkembangan teknologi informasi yang ada.
\end{abstract}

Kata kunci : Aplikasi, Kenaikan Gaji Berkala, Guru

\begin{abstract}
The Department of Education and Culture of Dumai City is one of the government agencies engaged in the field of education and in it there is a periodic salary increase activity. In data processing periodic salary increases are still using the manual method by looking at the salary table, so in making SK the salary increase requires a relatively long time. until now the Department of Education and Culture of the City of Dumai is still experiencing difficulties in finding the data file of teachers $S D$ who propose periodic salary increases, as well as the slow process of submitting periodic salaries because they still use the manual system. Therefore we need an application to provide solutions to these problems. In this research, the application that will be developed is the application of periodic salary increases at the Department of Education and Culture of the City of Dumai, so that it can be developed further for the progress and interests of the agencies along with the development of existing information technology.
\end{abstract}

Keywords : Application, Periodic Salary Increase, Teacher.

\section{PENDAhuluan}

Dinas Pendidikan dan Kebudayaan Kota Dumai adalah salah satu instansi pemerintah yang bergerak di bidang pendidikan dan didalamnya terdapat kegiatan kenaikan gaji berkala. Kenaikan Gaji Berkala merupakan kenaikan gaji yang diberikan kepada Pegawai Negeri Sipil (PNS) yang telah mencapai masa kerja golongan yang ditentukan untuk kenaikan gaji berkala yaitu setiap 2 tahun sekali dan apabila telah memenuhi persyaratan yang berlaku. 
I N F O R M A I I A

Jurnal Informatika, Manajemen dan Komputer, Vol. 13 No. 1 , Mei 2021

eISSN :2580 - 3042

pISSN : $1979-0694$

Saat ini sistem yang digunakan untuk kenaikan gaji berkala memiliki beberapa kelemahan, seperti relatif sulit menemukan arsip data kenaikan gaji berkala SD khususnya guru, membutuhkan waktu cukup lama dalam hal pembuatan SK kenaikan gaji berkala dan laporan data guru yang mengajukan kenaikan gaji berkala, kurang efektif dan efisien karena kemungkinan besar terjadi kesalahan dalam memasukkan data, penghitungan gaji dan penghitungan waktu pengajuan, proses penyimpanan data tidak efektif karena data yang tersimpan kemungkinan dapat terhapus.

Dari uraian permasalahan pada paragraf sebelumnya dibutuhkan adanya suatu sistem yang mampu mengatasi masalah yang timbul seperti mempermudah pendataan guru SD yang mengajukan kenaikan gaji berkala, memudahkan dalam mencari data guru SD yang mengajukan kenaikan gaji berkala, mempermudah pembuatan SK kenaikan gaji berkala dan laporan data guru yang kenaikan gaji berkala di Dinas Pendidikan dan Kebudayaan Kota Dumai, disamping itu sistem yang akan dibangun mampu mempermudah Operator SD Dinas Pendidikan dan Kebudayaan Kota Dumai dalam memproses data kenaikan gaji berkala, menyajikan SK kenaikan gaji berkala dan laporan kenaikan gaji berkala.

\section{a. Pengertian Sistem}

Menurut Jogiyanto HM (1999:1) di dalam jurnalnya (Priyanti, 2013), Sistem adalah suatu jaringan kerja dari prosedur-prosedur yang saling berhubungan, berkumpul bersama sama untuk melakukan suatu kegiatan atau untuk menyelesaikan suatu sasaran tertentu.

Sistem merupakan suatu kumpulan atau himpunan dari unsur atau variabel - variabel yang saling terorganisasi, saling berinteraksi dan saling bergantung satu sama lain (Hanif, 2007:3)

\section{b. Informasi}

Menurut Jogianto HM (1991:692) di dalam jurnalnya (Priyanti, 2013), Informasi adalah sebagai hasil dari pengolahan data dalam suatu bentuk yang lebih berguna dan lebih berarti bagi penerimanyayang menggambarkan suatu kejadian-kejadian (event) yang nyata (fact) yang digunakan untuk pengambilan keputusan.

Infomasi merupakan hasil pengolahan data sehingga menjadi bentuk yang penting bagi penerimanya dan mempunyai kegunaan sebagai dasar dalam pengambilan keputusan yang dapat

dirasakan akibatnya secara langsung saat itu juga atau secara tidak langsung pada saat mendatang. (Edhy Sutanta, 2003:13)

\section{c. Aplikasi}

Menurut (Juansyah Andi, 2015) di dalam Jurnalnya (Rubiati Nur, 2019) Secara istilah pengertian aplikasi adalah suatu program yang siap untuk digunakan yang dibuat untuk melaksanankan suatu fungsi bagi pengguna jasa aplikasi serta penggunaan aplikasi lain yang dapat digunakan oleh suatu sasaran yang akan dituju.

\section{d. Basis Data (Database)}

Menurut Arifin (2010:3) di dalam jurnalnya (Priyo Sutopo, Dedi Cahyadi, 2016), Basis Data merupakan kumpulan dari data yang saling berhubungan antara satu dengan yang lainnya. Basisdata atau database merupakan salah satu komponen yang penting dalam sistem infomasi, karena berfungsi sebagai basis penyedia infomasi bagi pemakainya, sistem basis data adalah suatu sistem informasi yang mengintegrasikan kumpulan dari data yang saling berhubungan dengan yang lainnya dan untuk membuatnya tersedia beberapa aplikasi yang bermacam-macam dalam suatu sistem organisasi.

\section{e. PHP}

Menurut Murya (2017: 1) di dalam jurnalnya (Adrianto Sukri, 2019), PHP merupakan bahasa pemrograman untuk membuat web yang bersifat server - side scripting. PHP memungkinkan untuk membuat halaman web yang bersifat dinamis. Sistem manajemen basis data yang sering digunakan bersama PHP adalah MySQL namun PHP juga mendukung sistem manajemen database Oracle, Microsoft Access, Interbase, d-base, PostgreSQL, dan sebagainya.

\section{f. XAMPP}

Menurut Santoso (2017:86), Xampp merupakan alat bantu yang menyediakan paket perangkat lunak ke dalam satu buah paket. Dengan menginstall XAMPP maka tidak perlu lagi melakukan instalasi dan konfigurasi web server Apache, PHP dan MySQL secara manual. XAMPP akan menginstalasi dan mengkonfigurasikannya secara otomatis atau auto konfigurasi.

\section{g. ASI}

Menurut Ismael (2017:149), Aliran 
I N F ORM A T I K

Jurnal Informatika, Manajemen dan Komputer, Vol. 13 No. 1 , Mei 2021

eISSN :2580 - 3042

pISSN : $1979-0694$

Sistem Informasi (ASI) merupakan bagan yang menunjukan arus pekerjaan serta keseluruhan dari sistem. Bagan ini menjelaskan urutan dari prosedur - prosedur yang ada dalam sistem.

Tabel 1. Simbol-simbol Aliran Sistem Infomasi (ASI)

\begin{tabular}{|c|c|c|}
\hline $\mathrm{NO}$ & SIMBOL & KETERANGAN \\
\hline 1. & & Proses Komputer \\
\hline 2 & & Dokumen \\
\hline 3. & & Penghubung \\
\hline 4. & & Garis Alir \\
\hline 5. & & Output Monitor \\
\hline 6. & & Manual Proses \\
\hline 7. & & File Storage \\
\hline 8. & & $\begin{array}{l}\text { Penghubung Antar } \\
\text { Halaman }\end{array}$ \\
\hline 9. & & $\begin{array}{l}\text { Input Menggunakan } \\
\text { Keyboard }\end{array}$ \\
\hline 10 & & $\begin{array}{l}\text { Input-Output } \\
\text { Menggunakan } \\
\text { Disket }\end{array}$ \\
\hline
\end{tabular}

Sumber : Ismael (2017:149)

\section{h. Diagram Konteks (Diagram Context)}

Diagram Konteks merupakan suatu diagram alir tingkat tinggi yang menggambarkan seluruh jaringan, masukan dan keluaran. Sistem yang dimaksud adalah untuk

menggambarkan sistem yang sedang berjalan. (Indrajani, S.Kom., MM, 2015:14)

Menurut (Tanjung Irwandi, 2017:46), Context Diagram adalah gambaran umum tentang suatu sistem yang terdapat dalam suatu organisasi yang memperlihatkan batasan (boundary) sistem, adanya interaksi antara eksternal entity dengan suatu sistem dan informasi secara umum mengalir diantara entity atau sistem.

\section{i. Data Flow Diagram (DFD)}

Data Flow Diagram (DFD) merupakan suatu diagram yang menggambarkan alir data dalam suatu entitas ke sistem atau sistem ke entitas. DFD juga dapat diartikan sebagai teknik grafis yang menggambarkan alir data dan transformasi yang digunakan sebagai perjalanan data dari input atau masukan menuju keluaran atau output. (Andrea Adelheid, 2012:46)

Menurut Indrajani (2015:27) Data Flow Diagram (DFD) adalah sebuah alat yang menggambarkan aliran data sampai sebuah sistem selesai, dan kerja atau proses dilakukan dalam sistem tersebut .

Tabel 2. Simbol-simbol DFD

\begin{tabular}{|c|l|l|}
\hline $\begin{array}{c}\text { DeMarco } \\
\text { dan Yourdan }\end{array}$ & \multicolumn{1}{|c|}{ Keterangan } & \multicolumn{1}{c|}{$\begin{array}{c}\text { Gane dan } \\
\text { Sarson }\end{array}$} \\
\cline { 2 - 3 } & $\begin{array}{l}\text { Source } \\
\text { (Kesatuan } \\
\text { Luar) }\end{array}$ \\
\hline & $\begin{array}{l}\text { Process } \\
\text { (Proses) }\end{array}$ & \\
\hline$\longleftarrow$ & $\begin{array}{l}\text { Data Flow } \\
\text { (Arus Data) }\end{array}$ & 4 \\
\hline & $\begin{array}{l}\text { Data Source } \\
\text { (Simpanan } \\
\text { Data) }\end{array}$ & $\square$ \\
\hline
\end{tabular}

Sumber : Indrajani, S.Kom., MM (2015:28)

\section{METODE PENELITIAN}

Metode penelitian yang digunakan dalam penelitian ini adalah metode deskriptif yaitu menggambarkan semua data yang kemudian 
I N F ORM A T I K

Jurnal Informatika, Manajemen dan Komputer, Vol. 13 No. 1 , Mei 2021

eISSN :2580 - 3042

pISSN : 1979 - 0694

dianalisa berdasarkan kenyataan yang sedang berlangsung dan memberikan pemecahan masalahnya.

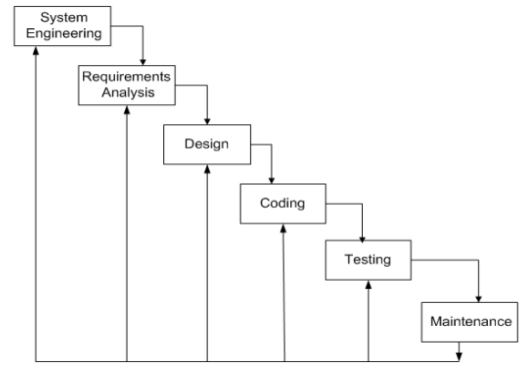

Feedback

Gambar 1. Metode Waterfall

Tahapan - tahapan yang terdapat dalam model waterfall adalah sebagai berikut :

1. System Engineering (Rekayasa Perangkat Lunak)

Pemodelan ini diawali dengan mencari kebutuhan dari keseluruhan sistem yang akan diaplikasikan ke dalam bentuk software yang akan digunakan untuk merancang suatu aplikasi yang berkaitan dengan kenaikan gaji berkala menggunakan bahasa pemrograman php.

2. Requirements Analysis

Dalam tahap ini merupakan analisa terhadap kebutuhan sistem. Pengumpulan data dalam tahap ini bisa di lakukan dengan wawancara atau survey ke admin bagian SD pada Dinas Pendidikan dan Kebudayaan Kota Dumai .

3. Design

Tahapan ini dilakukan sebelum coding, bertujuan untuk memberikan gambaran apa yang seharusnya dikerjakan dan bagaimana tampilannya. Hasil akhirnya berupa spesifikasi rancangan yang sangat rinci sehingga mudah diwujudkan pada saat pemograman.

4. Coding (Implementasi)

Pengkodean yang mengimplementasikan hasil desain ke dalam kode atau bahasa yang dimengerti oleh mesin komputer dengan menggunakan bahasa pemrograman tertentu.

5. Testing (Pengujian)

Melakukan pengujian yang menghasilkan kebenaran program. Proses pengujian berfokus pada logika internal perangkat lunak, memastikanbahwa semua pernyataan sudah diuji dan memastikan apakah hasil yang diinginkan sudah tercapai atau belum.

6. Maintenance (Perawatan)

Menangani perangkat lunak yang sudah selesai agar dapat berjalan lancar dan terhindar dari gangguan - gangguan yang dapat menyebabkan kerusakan.

\section{HASIL PEMBAHASAN}

a. Aliran Sistem Informasi (ASI)

Adapun Aliran Sistem (ASI) yang baru dapat digambarkan sebagai berikut :

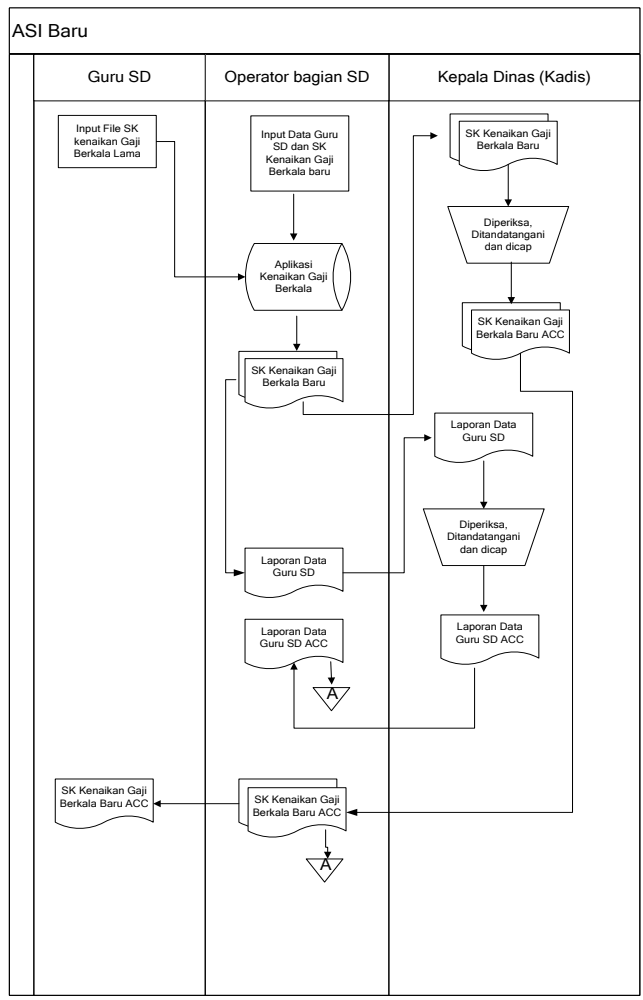

Gambar 2. ASI

\section{b. Context Diagram}

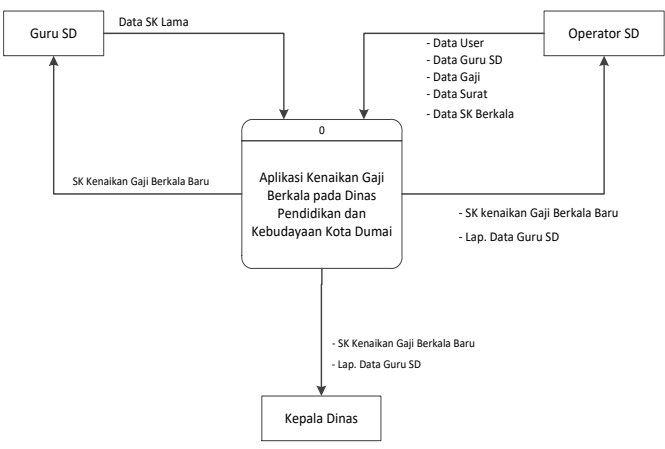

Gambar 3. Context Diagram 
I N F ORM A T I K

Jurnal Informatika, Manajemen dan Komputer, Vol. 13 No. 1 , Mei 2021

eISSN :2580 - 3042

pISSN : $1979-0694$

c. DFD

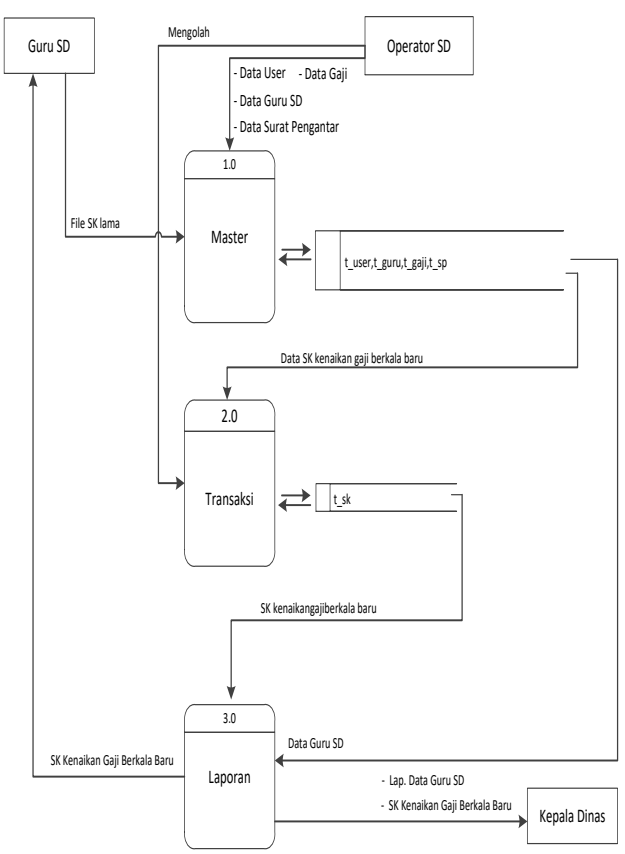

Gambar 4. DFD

\section{IMPLEMENTASI PROGRAM \\ a. Login Operator $S D$}

Jalankan aplikasi ini sebagai Operator SD dengan cara membuka pada browser mozila firefox / Google Chrome kemudian masukan alamat domain yang dituju. Masukan username dan password dengan benar maka aplikasi utama terbuka.

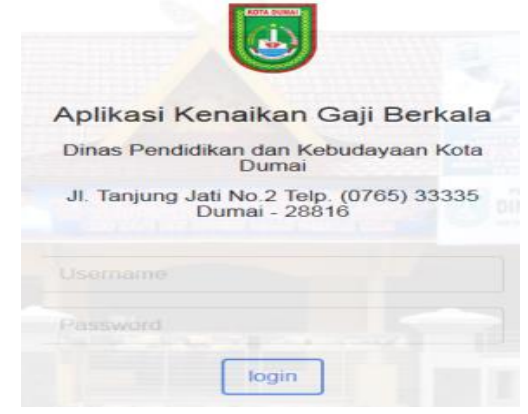

Gambar 5. Form Login Operator SD

\section{b. Form Login Guru SD}

Jalankan aplikasi ini sebagai Guru SD dengan cara membuka pada browser mozila firefox / Google Chrome kemudian masukan alamat domain yang dituju. Masukan username dan password dengan benar maka aplikasi utama terbuka.

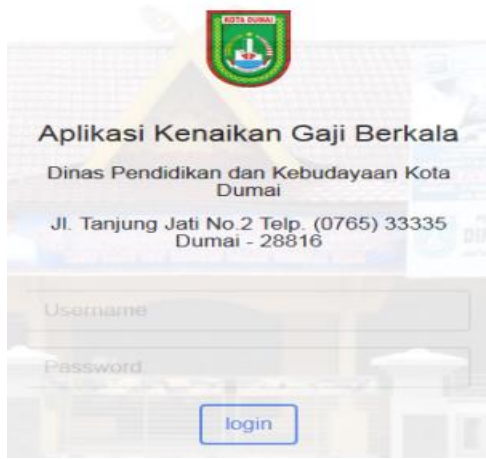

Gambar 6. Form Login Guru SD

\section{c. Form Input Data Guru SD}

Pada form ini operator SD dapat menambahkan data Guru SD. Berikut adalah petunjuk penggunaan form masukkan data Guru SD :

1. Pada form menu master

2. Kemudian klik Data Guru SD

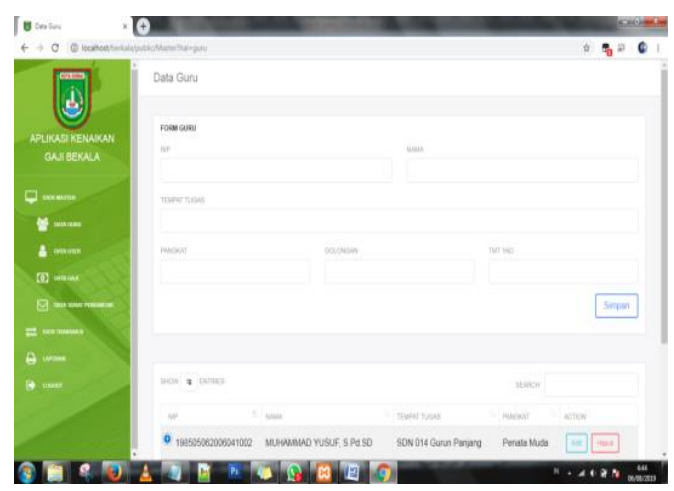

Gambar 7. Form Data Guru SD

3. Kemudian isi Data Guru SD untuk disimpan dengan mengklik simpan.

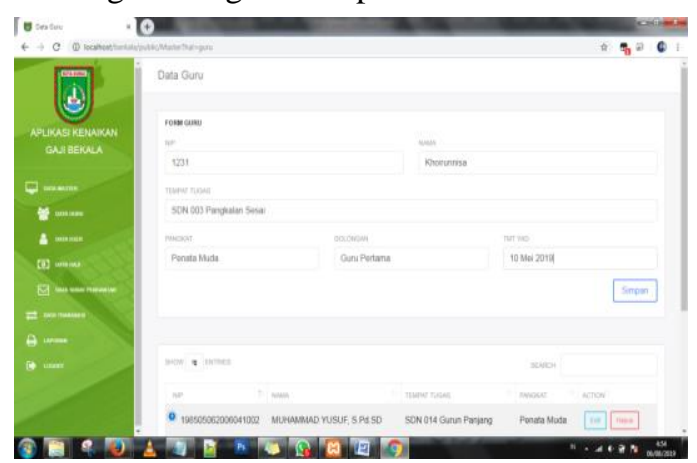

Gambar 8. Form Input Data Guru

\section{d. Form Input Data Gaji}

Pada form ini operator SD dapat menemukan Data Gaji. Berikut adalah petunjuk penggunaan form masukan data perusahaan : 
I N F ORM A T I K

Jurnal Informatika, Manajemen dan Komputer, Vol. 13 No. 1 , Mei 2021

eISSN :2580 - 3042

pISSN : $1979-0694$

1. Pada form menu master

2. Kemudian klik Data Gaji

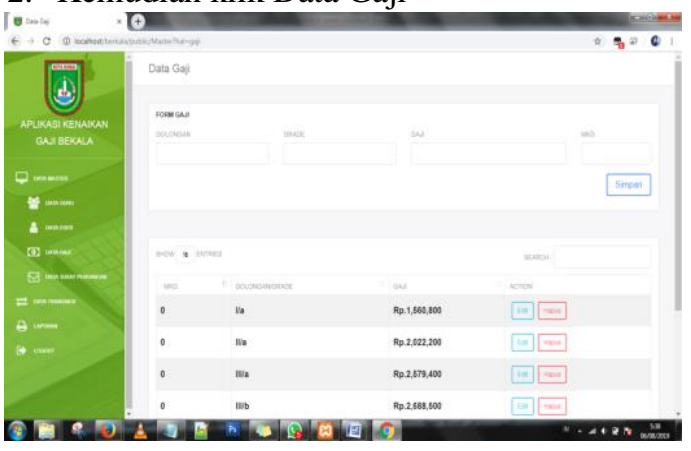

Gambar 9. Data Gaji

3. Kemudian isi Data Gaji untuk disimpan dengan mengklik Simpan.

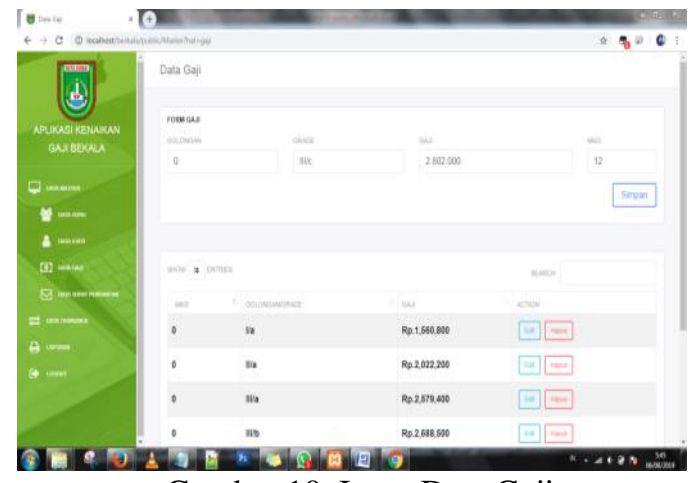

Gambar 10. Input Data Gaji

\section{e. Form Input Data Surat Pengantar}

Pada form ini operator SD dapat menemukan Data Surat Pengantar. Berikut adalah petunjuk penggunaan form Data Surat Pengantar :

1. Pada form menu master

2. Kemudian klik Data Surat Pengantar

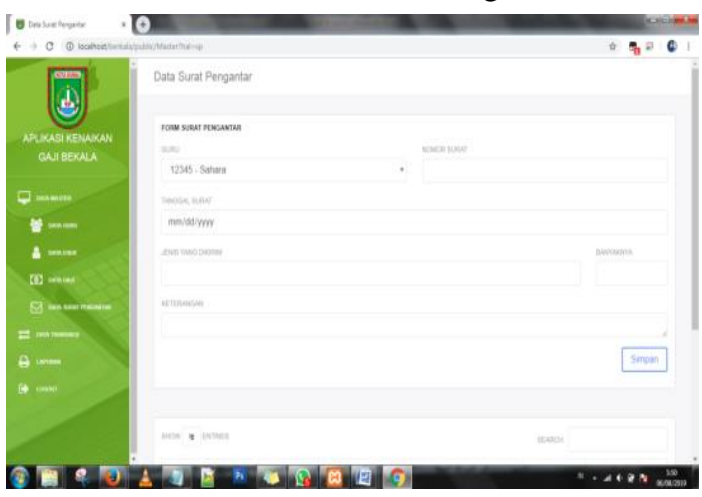

Gambar 11. Input Data Surat Pengantar

3. Kemudian isi Data Surat Pengantar untuk disimpan dengan mengklik Simpan.

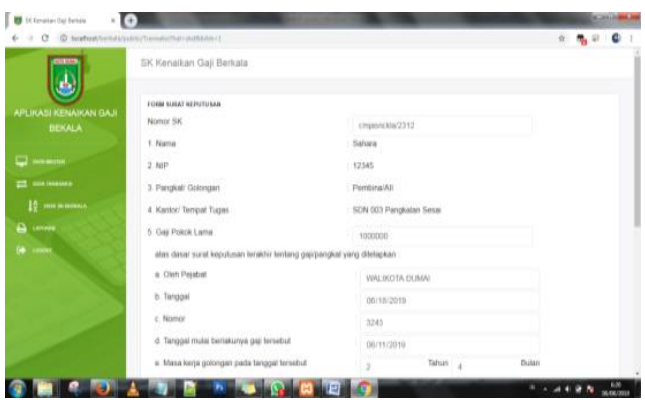

Gambar 12. Input Data Surat Pengantar

\section{f. Form Data Transaksi}

Pada form ini operator SD dapat menemukan Data Transaki SK Berkala. Berikut adalah petunjuk penggunaan form Data Transaksi :

1. Pada form Data Transaksi klik Data SK Berkala

2. Kemudian klik Buat SK Berkala.

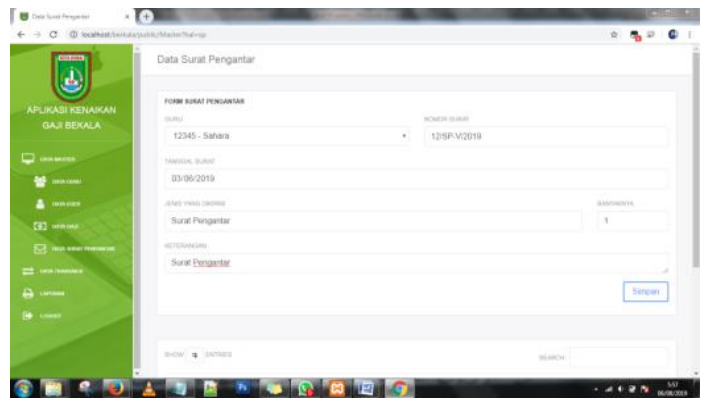

Gambar 13. Form Data Transaksi

g. Output Sistem

1. Laporan Data Guru SD Pertempat Tugas

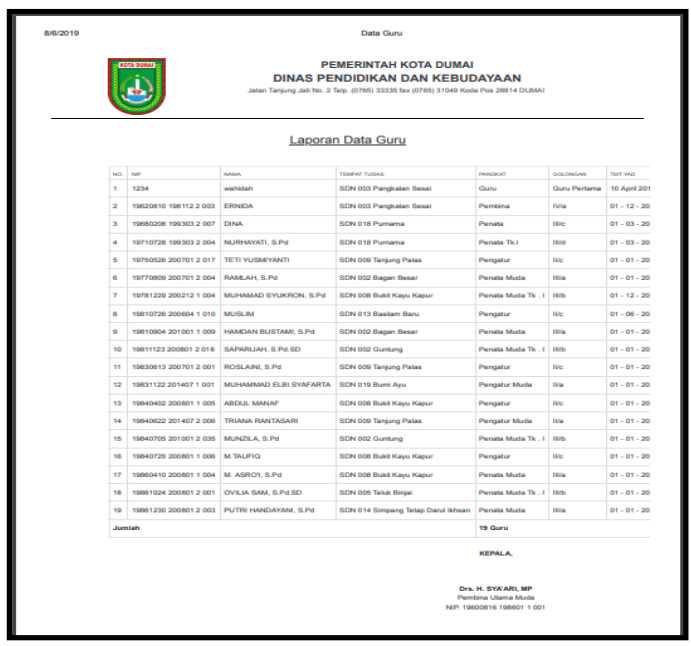

Gambar 14. Laporan Data Guru SD Pertempat Tugas 
I N F ORM A T I K

Jurnal Informatika, Manajemen dan Komputer, Vol. 13 No. 1 , Mei 2021

eISSN :2580 - 3042

pISSN : $1979-0694$

\section{Laporan Data Guru SD Pertanggal}

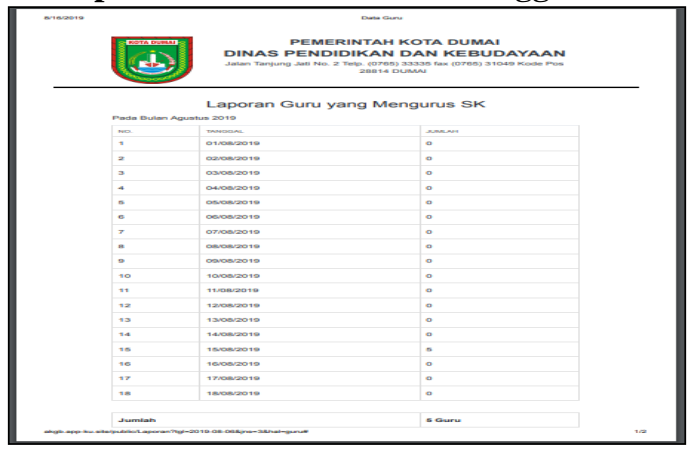

Gambar 15. Laporan Guru SD Pertanggal

\section{Laporan Data Guru SD Per Bulan}

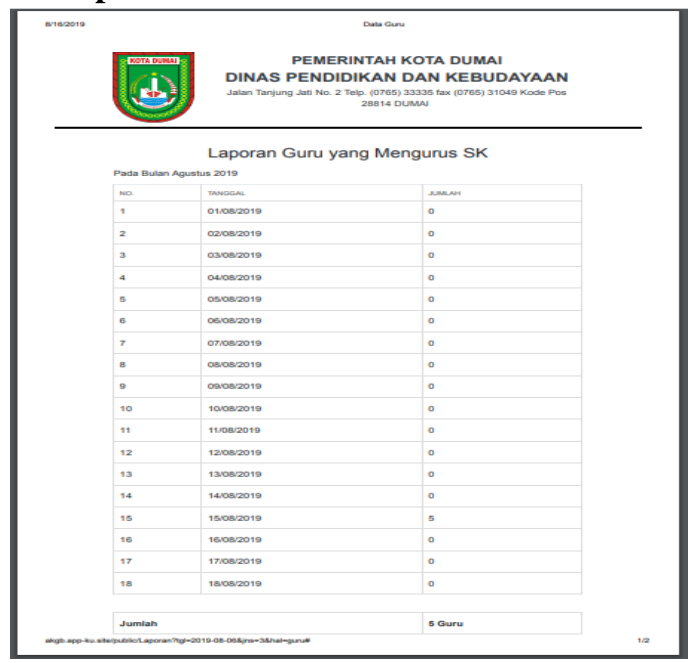

Gambar 16. Laporan Data Guru SD Perbulan

\section{Laporan Data Guru SD Pertahun}

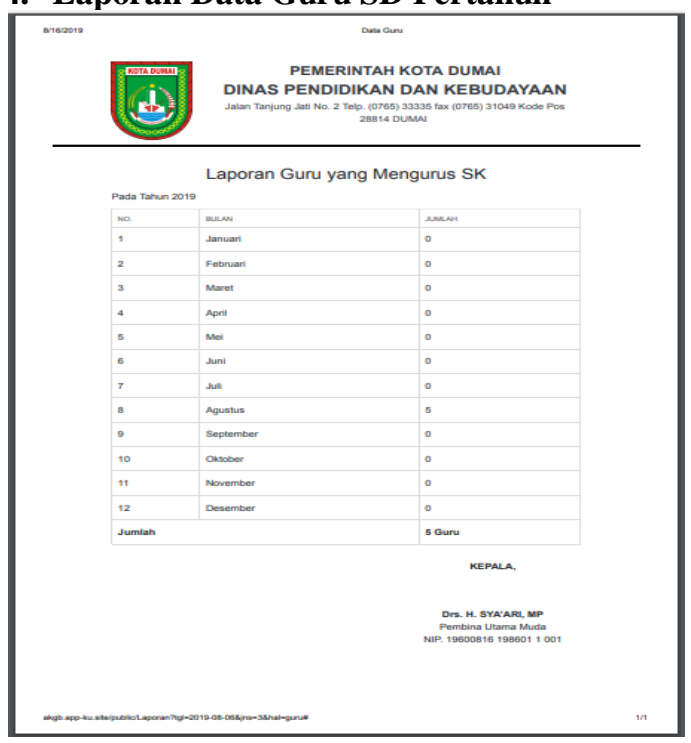

Gambar 17. Laporan Data Guru SD Pertahun

\section{SK Kenaikan Gaji Berkala}

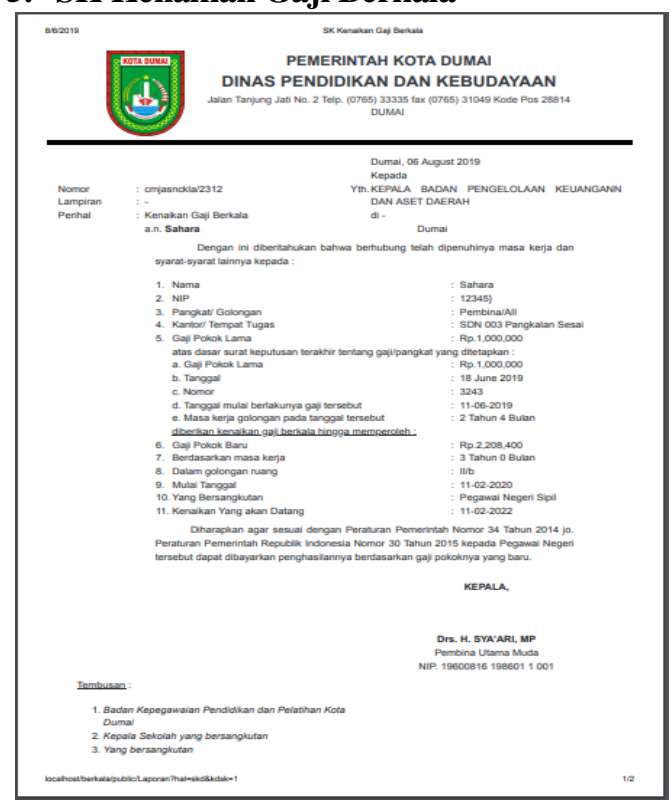

Gambar 18. SK Kenaikan Gaji Berkala

\section{KESIMPULAN}

Berdasarkan penelitian yang telah dilakukan dengan mengamati dan menganalisa sistem pengolahan data digunakan serta dilandasi oleh teori - teori dan alat - alat yang digunakan berkaitan dengan penelitian. Maka dapat disimpulkan bahwa dirasakan perlu untuk diterapkannya sistem komputer dengan menggunakan suatu paket aplikasi komputer sebagai pengganti sistem lama yang ditangani. Maka berdasarkan uraian-uraian di atas dan perancangan sistem di maksud di dalam penelitian ini, maka dapat diambil beberapa kesimpulan :

1. Transaksi cukup memanggil nip nya saja dengan demikian tidak perlu berulang ulang menginput data, karena telah diambil di database masternya maka pekerjaaan menjadi mudah.

2. Mudah untuk mencari informasi dengan mengetik data di form searching dengan demikian mudah mencari data.

3. Cepat dan mudah membuat laporan karena setiap data transaksi sudah tersusun dalam laporan sesuai yang diinginkan.

\section{REFERENSI}

Adrianto Sukri, Y. N. F. (2019). SISTEM PENILAIAN SISWA KURIKULUM 2013 PADA SDN 007 BAGAN BESAR MENGGUNAKAN. Jurnal Informatika, Manajemen Dan Komputer, 11(1), 21-29. 
I N F ORM A T I K

Jurnal Informatika, Manajemen dan Komputer, Vol. 13 No. 1 , Mei 2021

eISSN :2580 - 3042

pISSN : 1979 - 0694

Andrea Adelheid, K. N. (2012). Pintar Menguasai PHP MYSQL. Jakarta Selatan.

Hanif, A. fatta. (2007). Analisis dan Perancangan Sistem Informasi untuk Keunggulan Bersaing Perusahaan dan Organisasi Modern. Yogyakarta.

Indrajani, S.Kom., MM. (2015). Database Design. Jakarta.

Ismael. (2017).

PENGEMBANGAN APLIKASI SMS GATEWAY UNTUK INFORMASI PENDAFTARAN PESERTA DIDIK BARU . Indonesian Jurnal Onf Networking and Security (IJNS), 141-150.

Priyanti, D. (2013). Sistem Informasi Data Penduduk Pada Desa Bogoharjo Kecamatan Ngadirojo Kabupaten Pacitan. IJNS - Indonesian Journal on Networking and Security, 2(Laporan), 1-7. https://doi.org/10.1123/IJNS.V2I4.181

Priyo Sutopo, Dedi Cahyadi, Z. A. (2016). SISTEM INFORMASI EKSEKUTIF. Jurnal Informatika Mulawarman, 11(1), 23.

Rubiati Nur, S. W. H. (2019). I n f o r m a t i k a. Jurnal Informatika, Manajemen Dan Komputer, 11(1), 62-70.

Santoso, R. N. (2017). Perencanaan dan Pengembangan Aplikasi Absensi Mahasiswa Menggunakan Smart Card Guna Pengembangan Kampus Cerdas ( Studi Kasus Politeknik Negeri Tanah Laut ). Jurnal Integrasi, 9(1), 84-91.

Tanjung Irwandi, D. S. (2017). Perancangan Sistem Informasi Rekam Medis Terpadu Dalam Upaya. Jurnal Intra-Tech, 1(1), 43-54. 